\title{
PLATAFORMAS ONLINE PARA A MEDIAÇÃO REMOTA NO ENSINO SUPERIOR PÚBLICO ANGOLANO EM TEMPOS DE COVID-19
}

\section{Online Platforms for Remote Mediation in Angolan Public Higher Education in Times of COVID-19}

\begin{abstract}
Resumo: No cenário educacional angolano, com a publicação do recente Decreto Presidencial $\mathrm{n}^{\circ} 59 / 20$, de 3 de março de 2020, que aprova o regulamento das modalidades de ensino a distância e semipresencial no subsistema de ensino superior, o país reforça o ensino com o recurso às tecnologias digitais, como medidas de apoio ao ensino presencial, uma medida oportuna, particularmente em situação de emergência de saúde pública, como o da pandemia de COVID-19. Este artigo objetiva apresentar alternativas de ensino-aprendizagem através de plataformas online gratuitas Google Classroom (ferramenta assíncrona), Meet e Zoom (ferramentas síncronas) e suas potencialidades pedagógicas para o ensino remoto no ensino superior público angolano no período de COVID-19. Trata-se de uma pesquisa diagnóstica, exploratória, descritiva e qualitativa, através da aplicação de um questionário online aos professores do Instituto Superior Politécnico do Cuanza Sul, a fim de explorar suas possíveis percepções em relação ao uso de plataformas online no período de pandemia. A partir da análise de conteúdos do questionário, há evidências de resultados positivos para o uso de plataformas online como o Google Classroom, Meet e Zoom no processo de ensino-aprendizagem no período de pandemia e que existe carência de oferta de formação para os professores sobre o uso de tecnologias digitais educacionais nesse período. Espera-se com este estudo auxiliar os professores universitários angolanos que pretendem alternar suas aulas presenciais por meio do ensino remoto e que certos resultados de aprendizagem podem ser alcançados durante e após o período de COVID-19.
\end{abstract}

Palavras-chave: COVID-19. Educação Superior. Plataformas online. Ensino Remoto.

\begin{abstract}
In the Angolan educational scenario, with the publication of the recent Presidential Decree No. 59/20 of march 3, 2020, which approves the regulation of distance and semi-faceto-face teaching modalities in the higher education subsystem, the country reinforces education with the use of digital technologies, as measures to support face-to-face education, a timely measure, particularly in a public health emergency, such as the COVID-19 pandemic. This paper aims to present teaching-learning alternatives through free online platforms Google Classroom (asynchronous tool), Meet and Zoom (synchronous tools) and their pedagogical potential for remote teaching in angolan public higher education in the period of COVID-19. This is a diagnostic, exploratory, descriptive and qualitative research, through the application of an online questionnaire to the teachers of the Polytechnic Higher Institute of South Cuanza,

\footnotetext{
1 Professor de Informática do Instituto Superior do Politécnico do Cuanza Sul (ISPCS, Angola). Mestre em Tecnologias da Informação e Comunicação pela Universidade Federal de Santa Catarina (UFSC). Doutorando em Educação Científica e Tecnológica pela UFSC. ORCID: https://orcid.org/0000-0002-4550-7476. E-mail:herculano.henriques@gmail.com.
} 
in order to explore their possible perceptions regarding the use of online platforms in the pandemic period. From the analysis of contents of the questionnaire, there is evidence of positive results for the use of online platforms such as Google Classroom, Meet and Zoom in the teaching-learning process during the pandemic period and that there is a lack of training for teachers on the use of digital educational technologies in this period. It is expected that this study will assist angolan university teachers who intend to alternate their classroom classes through remote education and that certain learning outcomes can be achieved during and after the COVID-19 period.

Keywords: COVID-19. Higher Education. Online platforms. Remote Teaching.

\section{Introdução}

A COVID-19 é a designação da doença causada pelo vírus SARS-CoV-2, que se alastrou rapidamente no mundo inteiro. Destaca-se que esta doença teve seu início na Ásia, em Wuhan, província de Hubei, na China, com o primeiro caso notificado dia 17 de novembro de 2019. Após o continente asiático, a COVID-19 passou pela Europa, Américas, Oceania e chegou à África. Conforme WHO (2020), Joye, Moreira e Rocha (2020), devido à sua velocidade de propagação e infecção em nível exponencial, sem vacina, casos confirmados em massa ocorreram em todo o mundo, que no dia 11 de março de 2020, a Organização Mundial da Saúde (OMS) declarou a COVID-19 uma pandemia.

A OMS indicou que, para se combater efetivamente a COVID-19 e preservar vidas, os países deveriam fazer isolamento social, evitar aglomerações de pessoas e intensificar os hábitos saudáveis de higiene, como lavar as mãos corretamente (WHO, 2020). O relatório produzido por Sanz, Sainz e Capilla (s/d) sobre efeitos da crise de COVID-19 refere que na educação a OMS, "[...] elevou a situação de emergência de saúde pública ocasionada pela COVID-19". Consta no documento que "[...] até essa altura, muitos países já tinham começado a adotar medidas para tentar travar a propagação do vírus, entre elas o encerramento dos estabelecimentos de ensino".

A título de exemplo, antes da chegada do coronavírus (COVID-19) na Angola, alunos da educação básica e universitários de instituições públicas e privadas tiveram suas aulas suspensas por tempo indeterminado; professores foram dispensados de suas atividades acadêmicas sem recomendação para efetuar trabalho remoto. Mais tarde, a ministra do ensino superior, ciência, tecnologia e inovação, por meio do Decreto Executivo $n^{\circ}$ 2/20, de 19 de março de 2020, reforçou e recomendou a suspensão de todas as atividades letivas nas Instituições de Ensino Superior (IES).

Em 21 de março de 2020, Angola é surpreendida pelo primeiro caso confirmado do coronavírus (COVID-19) e tem apresentado tantos casos positivos. Como forma de diminuir a propagação do vírus e melhor controle da doença, o governo local determinou o encerramento das instituições de ensino, através do Decreto Presidencial da República $n^{\circ} 81 / 20$, de 25 de março de 2020, que declara o Estado de Emergência Nacional na Angola e introduziu medidas de prevenção. "Uma das medidas que consta nesse decreto é a suspensão das aulas em todas as instituições públicas e privadas, desde o ensino pré-escolar até ao ensino universitário". Mais tarde, o decreto anterior foi prorrogado pelo Decreto $n^{\circ}$ 97/20, de 9 de abril de 2020, por mais um período de 15 dias. Entretanto, "foram mantidos inicialmente os serviços e atividades essenciais inerentes à oferta de insumos e materiais necessários à sobrevivência, saúde, abastecimento e segurança da população". 
Todavia, o impacto direto da COVID-19 em todos os setores do país (economia, saúde, educação, indústria, entre outros) e no meio de tantas incertezas, levou o governo angolano a declarar Situação de Calamidade Pública, por meio do Decreto Presidencial da República $n^{\circ}$ 142/20, de 25 de maio de 2020. Nessa situação de emergência de saúde pública, o distanciamento físico e o isolamento social se apresentam como alternativas eficazes para evitar o colapso do sistema de saúde, bem como para a redução dos crescentes casos de contaminações e óbitos ocorridos diariamente no mundo (SAMPAIO, 2020).

Entretanto, surge a necessidade de olhar para o contexto educacional angolano de modo a transformar e inovar o modelo tradicional de ensino vigente nas IES públicas. Um dado a ser destacado é o de que, as aulas no ensino superior sempre foram ministradas presencialmente e as IES não mostravam tanto interesse em integrar plataformas online para apoiar o processo ensino-aprendizagem. A situação mundial imposta pela pandemia de COVID-19 revelou uma realidade desafiadora para o ensino superior público no país, no que se refere a carência de infraestruturas tecnológicas (por exemplo, ambientes virtuais de ensino e aprendizagem, internet banda larga), dificuldade de acesso a recursos tecnológicos por parte dos alunos e a falta de equipamentos para os professores.

Na Angola, com a publicação do recente Decreto Presidencial da República no 59/20, de 3 de março de 2020, que aprova o regulamento das modalidades de ensino a distância (EaD) e semipresencial no subsistema de ensino superior angolano, destaca o uso de Tecnologias Digitais de Informação e Comunicação (TDIC) para mediação remota do ensino. Face ao isolamento físico e social causado pela COVID-19, as TDIC servem como alternativa ao ensino presencial, já que a "situação vivenciada atualmente possui desfecho imprevisível e a duração do isolamento social tem a ver com a extensão e a intensidade da infecção". Abraçando essa linha, a ministra do ensino superior, ciência, tecnologia e inovação autoriza, em caráter excepcional, a "substituição das disciplinas ou aulas presenciais por aulas e atividades letivas que utilizem recursos educacionais digitais ou outros meios convencionais enquanto durar a situação de pandemia de COVID-19". Contudo, a substituição de aulas presenciais no ensino superior público, por meio do ensino remoto, representa uma inovação e um desafio no cenário educacional angolano.

Para alguns, estamos convivendo em dois mundos, um presencial e outro digital, em que as TDIC estão em toda parte. Essas serviriam como canais para alguns serviços ocorrerem, tais como: trabalhos não essenciais à população, que poderiam ocorrer em casa (home office), e as atividades educacionais remotas com o intuito de diminuir as dificuldades de acesso à educação em um momento emergencial. Para outros, o uso dessas tecnologias é algo impensável diante do quadro de desigualdade social e do caos sanitário e financeiro promovido pela pandemia (JOYE; MOREIRA; ROCHA, 2020).

Há necessidade dos espaços de educação passarem por uma reconfiguração, no sentido de tornarem as relações do ensinar e do aprender, mais dinâmicas em consonância com as possibilidades inerentes a inserção das tecnologias digitais (NOVELLO; JUNIOR; RIBEIRO, 2020). O "distanciamento social e a quarentena foram projetados para reduzir, restringir a circulação e as interações entre pessoas" (WILDER-SMITH; FREEDMAN, 2020). Esse distanciamento lança as bases para fortalecer a aprendizagem mediada por tecnologias. As aplicações inovadoras possibilitam novos paradigmas para produção de saberes através da utilização de ferramentas digitais e de interações sociais não presenciais (CARNEIRO; GARCIA; BARBOSA, 2020).

Para tanto, é importante que as instituições constituam, em seu interior, um corpo docente com formação específica (técnica e metodológica) para trabalhar com essas 
tecnologias, assim como estrutura física com equipamentos e mobiliários adequados e uma equipe de gestão que coordene as ações no sentido que esteja contemplado no projeto pedagógico da instituição (NOVELLO; LAURINO, 2012).

Uma vez que os espaços educacionais presenciais estão fechados, há uma demanda em aberto em relação à aprendizagem. Esse tema ocupa espaço nas discussões educacionais na atualidade, e a saída óbvia é a internet e os equipamentos a ela conectados. Mas o debate não se limita aos meios, mas avança para as questões do currículo e a necessidade de mudança de comportamento dos professores, das instituições e dos alunos (CARNEIRO; GARCIA; BARBOSA, 2020). Nesse sentido, De Almeida e Valente (2012) observam que a adaptação das tecnologias aos planos pedagógicos se constitui, mas que as mídias envolvem informações, relações culturais, linguagens, tempos e espaços. Essas abordagens geralmente apresentam tecnologias de comunicação como ferramentas que inovam práticas educativas, pois permitem maior flexibilidade nos métodos de aprendizagem (CARNEIRO et al., 2019).

\begin{abstract}
As ferramentas tecnológicas educacionais como a internet já eram populares antes mesmo do distanciamento social ser adotado pelas instituições de ensino. Elas vinham atendendo a sociedade mundial e instituições como metodologia de ensino e aprendizagem. Essas inovações tecnológicas já vinham suprindo lacunas, sociais e educacionais, juntando a tecnologia e a educação e proporcionando mecanismos de evolução a fim de atender as demandas sociais educativas. As tecnologias permitem a difusão do conhecimento e o compartilhamento de informações e quem quer que esteja conectado à web pode acessar milhões de informações apenas com um clique. As inovações tecnológicas e a internet transformaram a forma de difundir novos conhecimentos (CARNEIRO; GARCIA; BARBOSA, 2020, p. 4).
\end{abstract}

No que concerne aos processos a serem desenvolvidos, modelos híbridos e metodologias ativas ${ }^{2}$ têm sido sugeridos (BACICH; MORAN, 2018), pois além de motivadores promovem a interação entre os sujeitos seja online ou presencial, tornando-os mais independentes e efetivos no desenvolvimento e consolidação de suas habilidades e competências. Mas também, com a alarmante situação mundial, a utilização de metodologias ativas (MARIN et al., 2010) torna-se mais uma possível ferramenta no desenvolvimento do conhecimento. Diversas instituições que ainda estavam resistentes ao ensino híbrido ${ }^{3}$ e/ou metodologias ativas terão a oportunidade de avaliar e testar uma diversidade de ferramentas e métodos e realizarem a educação a partir de experiências positivas (CARNEIRO; GARCIA; BARBOSA, 2020).

Segundo "os últimos dados divulgados pela Organização das Nações Unidas para a Educação, a Ciência e a Cultura (UNESCO), órgão que monitora os impactos da pandemia na educação, o fechamento de instituições de ensino afeta diretamente mais de $72 \%$ da população estudantil no mundo" (UNESCO, 2020). Jacinto, De Campos e De Campos (2020) refletem sobre os aspectos relevantes da complexa problemática e responsabilidade do encerramento das instituições escolares em situações de pandemia como a da COVID-19, nos países de recursos

\footnotetext{
${ }^{2}$ Metodologia ativa de aprendizagem é um processo onde o aluno está, de fato, no centro do seu processo de aprendizagem, participando ativamente e sendo protagonista na construção de seu conhecimento.

${ }^{3}$ Ensino híbrido é a metodologia que combina aprendizado online com o offline, em modelos que mesclam momentos em que o aluno estuda sozinho, de maneira virtual, e paralelamente em polos de estudo, em que a aprendizagem ocorre de forma presencial, valorizando a interação entre aluno e professor (JUNIOR; MONTEIRO, 2020, p. 6).
} 
limitados. Igualmente, estes autores citam que a maior parte dos pesquisadores é unânime em referir que as medidas da suspensão das aulas e do isolamento social têm implicações a curto e longo prazo sobre os intervenientes diretos e indiretos do processo de ensino-aprendizagem.

Relativamente às medidas e prerrogativas decretadas pelo governo angolano para o sistema de ensino, propostas de EaD "como solução massiva tem provocado acaloradas discussões, considerando que a inclusão digital ainda constitui um enorme gargalo". Pois, Angola é um país africano onde o acesso à internet é ainda dificultado, as condições de infraestruturas tecnológicas nas IES públicas não são das melhores, havendo instituições sem conexão à internet banda larga, não dispõem de plataformas online e ferramentas educacionais como auxílio ao ensino presencial. Regueiro et al. (2020) coloca que:

\begin{abstract}
A tentativa de suprir as necessidades da educação presencial por educação remota gerou uma reflexão sobre o uso das TDIC, iniciado ainda nos anos 90, e que está adquirindo forma, se aprimorando e se consolidando diante desse cenário específico de pandemia. A rotina presencial foi des(construída) / re(construída) em extrema velocidade e apresentada em tempo similar à educação presencial, com transmissões nos horários de aulas estabelecidos no início do semestre, viabilizadas pelas ferramentas digitais previamente citadas. A transmissão síncrona pelas diferentes plataformas digitais, vinculadas, em sua maioria, à IES, possibilita a colaboração e a participação de todos, pois, como complementação, as atividades são gravadas na sala de aula virtual da disciplina para oportunizar o acompanhamento pelos estudantes sem condições de assisti-las nos momentos pré-definidos (REGUEIRO et al., 2020, p. 109).
\end{abstract}

No âmbito educacional, houve a paralisação obrigatória de todos os setores, incluindo as IES, emergindo, por consequência, a necessidade de ressignificar o ensino presencial e dar espaço ao ensino remoto mediado por recursos tecnológicos e suas interfaces na educação superior nas diferentes áreas do conhecimento, como as TDIC por meio dos smartphones, tablets e notebooks com o uso da internet, que, em diferentes contextos e funcionalidades, tornaram-se parte dos desafios do cotidiano educacional (TELES et al., 2020). Preocupados com a defasagem da aprendizagem, pais e escolas questionam que os alunos não podiam deixar de estudar, seja qual for a idade. A educação escolar e acadêmica é uma atividade indispensável à sociedade, e a mesma não podia parar (JOYE; MOREIRA; ROCHA, 2020, p. 3).

Deste modo, a Associação das Universidades Africanas (AAU) divulgou, social no seu comunicado, seis precauções para encorajar as IES africanas a tomar as medidas necessárias para reduzir o impacto da COVID-19, entre as quais, recomenda, na sua terceira enunciação preventiva, que se deve "agir com urgência na implementação de métodos alternativos de ensino e aprendizagem, com recurso à tecnologia e outras técnicas de EaD” (AAU, 2020, p. 2).

Para Agostinho e Saveta (2020, p. 110), no contexto educativo angolano, mormente no subsistema de ensino superior, com a publicação do recente Decreto Presidencial $n^{\circ} 59 / 20$, de 3 de março de 2020, que aprova o regulamento das modalidades de $\mathrm{EaD}$ e semipresencial no subsistema de ensino superior, o país reforça o seu alinhamento às recomendações internacionais e regionais sobre a aceleração do ensino com o recurso às tecnologias, como medidas de apoio ao ensino presencial, uma medida oportuna, em particular em tempos de crise, como o da pandemia de COVID-19.

Partindo da necessidade de suprir o ensino presencial por ensino remoto em IES angolanas, este trabalho objetiva apresentar alternativas de ensino-aprendizagem através de 
plataformas online gratuitas Google Classroom (ferramenta assíncrona ${ }^{\mathbf{4}}$ ), Meet e Zoom (ferramentas síncronas ${ }^{5}$ ) e suas potencialidades pedagógicas para o ensino remoto no ensino superior público angolano no período de COVID-19.

\section{Tecnologia Educacional no Cenário Atual}

No âmbito internacional, a utilização de TDIC tem possibilitado a continuidade dos processos educacionais, tanto no ensino presencial quanto no $\mathrm{EaD}$, antes do aparecimento da pandemia de COVID-19. Por conseguinte, o panorama atual, do mundial ao local, exige a empregabilidade massiva de tecnologias educacionais e maior investimento em infraestruturas tecnológicas nas IES públicas.

Conforme refere a AAU, “[...] a maioria das universidades africanas ainda não aplicou o ensino e a aprendizagem com o apoio de tecnologias de informação - isso inclui também algumas universidades que possuem sistemas de gestão de e-Learning instalados nos seus campi" (AAU, 2020, p. 2). A Associação considera que a pandemia constitui uma oportunidade para que as "[...] IES se posicionem de forma decisiva para institucionalizar o ensino e a aprendizagem com base em tecnologias de informação" (AAU, 2020, p. 2).

Em IES angolanas, com a interrupção repentina das atividades letivas, por ocasião da COVID-19, foi insuficiente o nível de orientações metodológicas para a adoção imediata do uso das tecnologias no apoio ao ensino presencial (AGOSTINHO; SAVETA, 2020). Ademais, as IES públicas e privadas angolanas, tiveram que se reorganizar e replanificar as suas atividades, desenvolvendo planos para dar continuidade do processo educacional por meio de modalidades alternativas, portanto, utilizando plataformas online. Por exemplo, algumas IES privadas, já bem estruturadas e equipadas com ferramentas tecnológicas (internet, canais de comunicação online, sistema de gestão acadêmica), os professores passaram a produzir aulas ao vivo, compartilhamento de materiais escritos, vídeos e áudios com atividades e dicas de estudos, por meio do Facebook e WhatsApp, para aproximar os alunos.

Por outro lado, muitas escolas, de maneira geral sem planejamento ou capacidade, passaram a trabalhar os componentes curriculares de forma remota, independentemente do método ou do grau de competência para fazê-lo, em consideração ao fato de que muitos estão se aventurando pela primeira vez no EaD ou online (SAMPAIO, 2020, p. 7), como é o caso das IES públicas angolanas. Este autor acrescenta que, diversas dificuldades relacionadas ao uso das TDIC permeiam essas práticas, que vão desde a escassez de recursos, a submissão a formas improvisadas de mediação tecnológica, a inaptidão para produzir e disponibilizar conteúdos, até a falta de manejo, por parte do docente, em adaptar a rotina de trabalho e conciliar tudo isso com os cuidados domésticos e da família (SAMPAIO, 2020, p. 7).

Existem dois métodos distintos de ensinar por meio do e-Learning: síncrono e assíncrono. No método síncrono é quando o professor e o aluno estão em aula ao mesmo tempo, é o modelo que se assemelha ao ensino presencial. Já o assíncrono o professor e o aluno não estão em aula ao mesmo tempo, ministrado por meio de fórum ou e-mail (JÚNIOR;

\footnotetext{
${ }^{4}$ As ferramentas assíncronas são aquelas que não precisam de conexão simultânea em tempo real. Aprendizagem assíncrona é aquela cuja interação entre participantes (professores, tutores e alunos) não necessariamente ocorre ao mesmo tempo.

${ }^{5}$ As ferramentas síncronas são aquelas que precisam da participação do aluno e do professor ao mesmo tempo e no mesmo ambiente. Aprendizagem síncrona é aquela cuja interação entre participantes (professores, tutores e alunos) necessariamente ocorre ao mesmo tempo e no mesmo ambiente.
}

\# Tear: Revista de Educação Ciência e Tecnologia, v.10, n.1, 2021. 
MACHADO; SILVA, 2020, p. 4). O e-Learning ou aprendizagem eletrônica é a modalidade de ensino-aprendizagem que combina a ideia de EaD com o auxílio das avançadas TDIC, resultando na educação online.

Segundo Júnior, Machado e Silva (2020), “estima-se que o uso da tecnologia permite maior interação, com flexibilidade de tempo e espaço, melhora a qualidade da aprendizagem e otimiza a relação custo-benefício das partes". Um aspecto importante é que, para os alunos, a utilização de plataformas de ensino possibilita a ampliação e a motivação da investigação pessoal, levando-os a descobrir os diversos ângulos de um mesmo assunto (JÚNIOR; MACHADO; SILVA, 2020, p. 4). Neste cenário, o papel dos docentes é fundamental para o sucesso da aprendizagem, mais ainda do que o ambiente físico das universidades ou a infraestrutura tecnológica. Quando o poder estruturante de tempo e de lugar que as escolas proporcionam se dissolve e a aprendizagem online se torna o modo dominante, o papel dos professores não diminui (CARNEIRO; GARCIA; BARBOSA, 2020, p. 9).

Portanto, durante o período de isolamento social, aumenta ainda mais o desafio do uso, pelos docentes, de alternativas tecnológicas que podem ser usadas com finalidade educativa, a partir da prévia negociação com os estudantes, para responder à interação acadêmica virtual, o que tem merecido o devido encorajamento a partir da tutela do Ensino Superior, referindo-se como uma "[...] oportunidade para privilegiar o atendimento digital, a comunicação eletrônica e para usar as plataformas digitais de apoio ao ensino presencial" (SAMBO, 2020, p. 1).

$\mathrm{Na}$ Angola, diante da pandemia de COVID-19 e da aprovação do EaD pelo governo local, as IES públicas devem encarar o uso de plataformas online ou ambientes virtuais de ensino e aprendizagem como suporte ao ensino presencial. Por meio da instrução direta ou da orientação dada na aprendizagem autodirigida, em modo síncrono ou assíncrono, o professor continua sendo essencial na orientação da aprendizagem dos alunos e ele cria condições para que haja colaboração e aprendizagem para os professores oferecendo acesso aos recursos e plataformas online (CARNEIRO; GARCIA; BARBOSA et al. 2020, p. 9).

\section{Plataformas Online}

Atualmente, na Angola, face à situação forçada pela pandemia da COVID-19, muitas instituições "dependem fortemente de plataformas de videoconferência e/ou educacionais", para dar sequência às suas atividades e interagir com suas equipes de trabalho, ou seja, do uso de ferramentas para trabalho remoto.

As principais plataformas online e ferramentas educacionais existentes são Google, Google Classroom, Google Suite, Google Hangout, Google Meet, Jitsi Meet, Facebook, Onenote from Microsoft, Microsoft, SEQTA, Perfect Education, Google Drive/Microsoft Teams, Moodle, Zoom, Seesaw, ManageBac, Ed Dojo EdModo, Mediawijs, Youtube, Whatsapp, Ebscohost, Progrentis, PhET, Screencastify, RAZ Kids e IXL. Nota-se um conjunto de soluções pedagógicas que pode contribuir com o desenvolvimento de habilidades, competências e saberes dos alunos e professores, diante do isolamento físico e social provocado pela pandemia de COVID-19. Porém, sabe-se que nem todas essas plataformas são utilizadas com regularidade no território angolano, por falta de conhecimento dos professores.

Para este estudo definiu-se três (3) plataformas: Zoom, Meet e o Google Classroom. As duas primeiras por estarem entre as melhores plataformas de videoconferências e utilizadas com maior destaque na Angola, e a última surge como uma novidade para os professores angolanos. Por exemplo, o Google Classroom (Google Sala de Aula) é bastante conhecido no Brasil e tem sido utilizado com tanta frequência neste período de pandemia da COVID-19, segundo os 
estudos feitos por Dos Santos Silva, Andrade e Dos Santos (2020). A seção 4 apresenta mais informações sobre o recorte ou seleção dessas plataformas.

De modo geral, as plataformas Google Classroom, Zoom e Meet foram definidas para este estudo por serem adequadas para auxiliarem nos processos de ensino e aprendizagem e na transmissão de aulas em videoconferência durante o período de pandemia da COVID-19. São ferramentas online gratuitas que podem promover suas potencialidades pedagógicas para o ensino remoto e um processo formativo diferenciado no contexto angolano.

\subsection{Google Classroom ou Google Sala de Aula}

Google Classroom $^{6}$ é uma plataforma muito usada para o $\mathrm{EaD}$ e/ou mediação com metodologias ativas, por meio do ensino híbrido. É um ambiente virtual que gerencia os materiais e conteúdos para instituições de ensino e professores como forma de criar atividades de ensino. Além do uso em computadores, a plataforma dispõe da possibilidade de ser utilizada em smartphones e tablets, por meio de um aplicativo próprio, disponível na Google Play e App Store ${ }^{8}$.

Essa plataforma existe desde o ano de 2014 " [...] e que poucos docentes utilizavam como ferramenta educacional. Contudo, ela se tornou um dos principais instrumentos de atividades acadêmicas de assessoramento aos professores nesse tempo de surto sanitário no Brasil" (DOS SANTOS SILVA; ANDRADE; DOS SANTOS, 2020, p. 5). Abrindo um parênteses nesta citação, faço menção da relação desta pesquisa angolana com o Brasil pelo potencial de estudos feitos e publicados no Brasil, e, sendo um exemplo a seguir por outros países de língua oficial portuguesa, sobretudo, nos países africanos - e, pessoalmente, tem sido também o país de minhas formações de pós-graduação e de outras formações complementares por meio de plataformas online como Google Sala de Aula, Zoom, Meet e Moodle.

Assim, o também conhecido Google Sala de Aula, a plataforma mais escolhida para mediação remota, pois não necessita de instalação local e um servidor exclusivo. A ferramenta é online, abriga alunos e professores, facilitando a entrada (login) e a integração de diferentes recursos disponibilizados pelo próprio Google como: Gmail, Google Drive, Hangouts, Google Docs e Google Forms (GOOGLE CLASSROOM, 2020). Seu diferencial é o sistema de feedback que é oferecido para que o professor dê todo suporte aos alunos nas atividades, desde o início até o final do processo formativo (DOS SANTOS JUNIOR; DA SILVA MONTEIRO, 2020, p. 7).

O Google Classroom tem oferecido possibilidades de comunicação, interação e produção de conteúdos favoráveis ao processo de ensino-aprendizagem de modo que o uso do Classroom também pode beneficiar a instituição de ensino quando passa a ser o centro para a exploração de conteúdos de sala de aula e atividades destinadas aos alunos (IFTAKHAR, 2016).

O Google Classroom é uma plataforma online em que o professor organiza as turmas por ano (exemplo: $1^{\circ}, 2^{\circ}$ ou $3^{\circ}$ ) ou cursos (exemplo: licenciatura em enfermagem, engenharia informática ou agronômica), diversifica as formas de avaliações, guarda as atividades e orienta os trabalhos de acordo com a turma escolhida. O sistema de atividade ou postagem na plataforma gera automaticamente uma notificação direta no e-mail do aluno, deixando-o

\footnotetext{
${ }^{6}$ Site da ferramenta: https://classroom.google.com/

${ }^{7}$ Google Play: "serviço operacional Android de distribuição digital de aplicativos, jogos, filmes, programas de televisão, músicas e livros, desenvolvido e operado pela Google".

${ }^{8}$ App Store: "serviço de distribuição digital de aplicativos para o sistema operacional iOS, da Apple."

\# Tear: Revista de Educação Ciência e Tecnologia, v.10, n.1, 2021. 
sempre atualizado sobre os conteúdos inseridos no ambiente virtual, fator que possibilita maior a interação e engajamento entre a turma (GOOGLE CLASSROOM, 2020). Além disso, segundo Dos Santos Silva, Andrade e Dos Santos (2020), o professor acompanha o desenvolvimento intelectual do aluno de maneira efetiva, adicionando comentários, se necessário, e notas avaliativas.

A Figura 1 apresenta a página inicial do Google Classroom acessado por computador e smartphone.

Figura 1 - Página inicial do Google Classroom

\section{$\equiv$ Google Classroom}

四 Para corrigir $\square$ Calendário

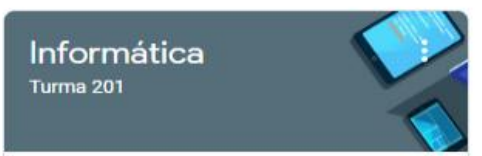

(2)

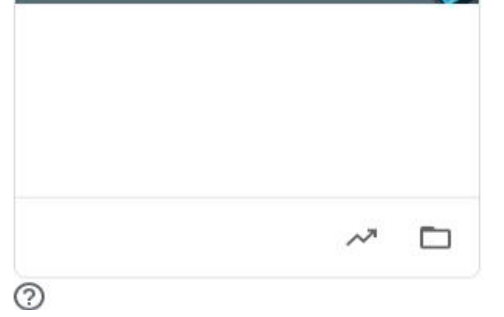

Fonte: Elaborado pelo autor (2020).
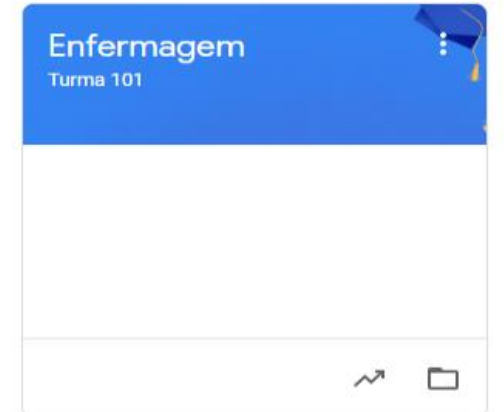

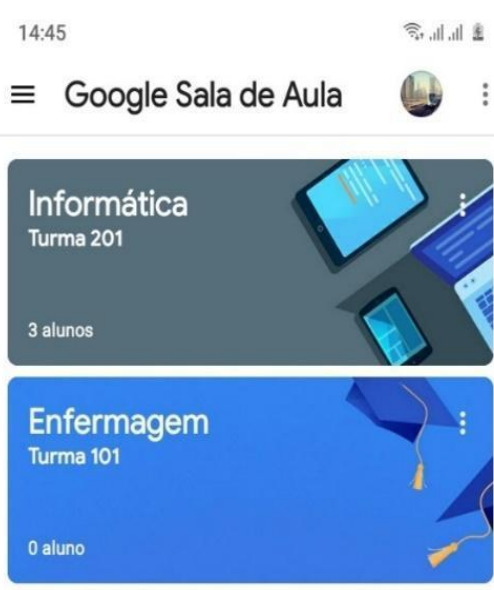
online:

a) Mural (Stream): neste campo, professores e alunos têm acesso às atualizações da plataforma, datas das postagens e últimas informações, assim também como comunicados e comentários (DOS SANTOS JUNIOR; DA SILVA MONTEIRO, 2020, p. 6), como mostra a Figura 2.

Figura 2 - Mural da turma no Google Classroom

$$
\begin{aligned}
& \text { Informática } \\
& \text { Turma 201 }
\end{aligned} \text { Stream Trabalhos da turma Pessoas Classificações }
$$

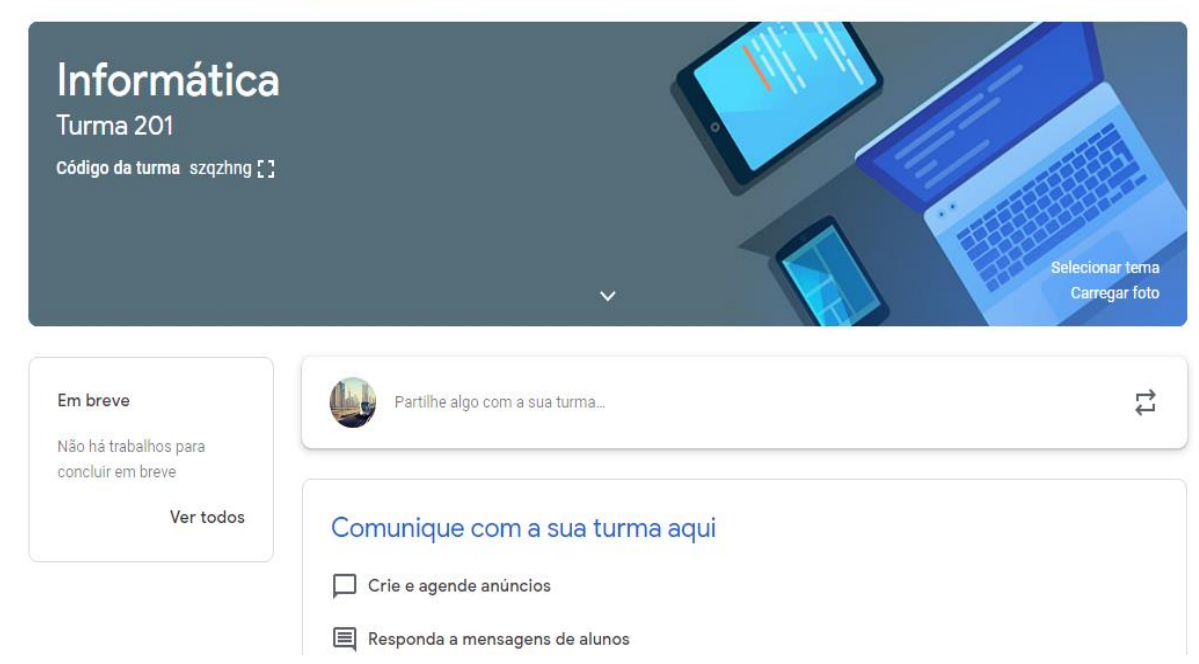

Fonte: Elaborado pelo autor (2020). 
b) Atividades (Trabalho): nessa área, o professor realiza as postagens. As atividades podem ser disponibilizadas de várias formas, a exemplo das opções dispostas na Figura 3. Em seguida, com a devolução da atividade ou da avaliação, "o docente pode disponibilizar uma nota a ser visualizada pelo aluno de forma imediata ou somente ao final da revisão. Também é gerada uma planilha para o controle acadêmico de todos os participantes" (DOS SANTOS JUNIOR; DA SILVA MONTEIRO, 2020, p. 6). Deste modo, todos os alunos recebem as notificações em seus e-mails, sobre a atividade indicada com a possibilidade de prazos estipulados reduzindo a probabilidade de descuido quanto ao tempo de entrega.

Figura 3 - Tipos de atividades efetuadas no Google Classroom

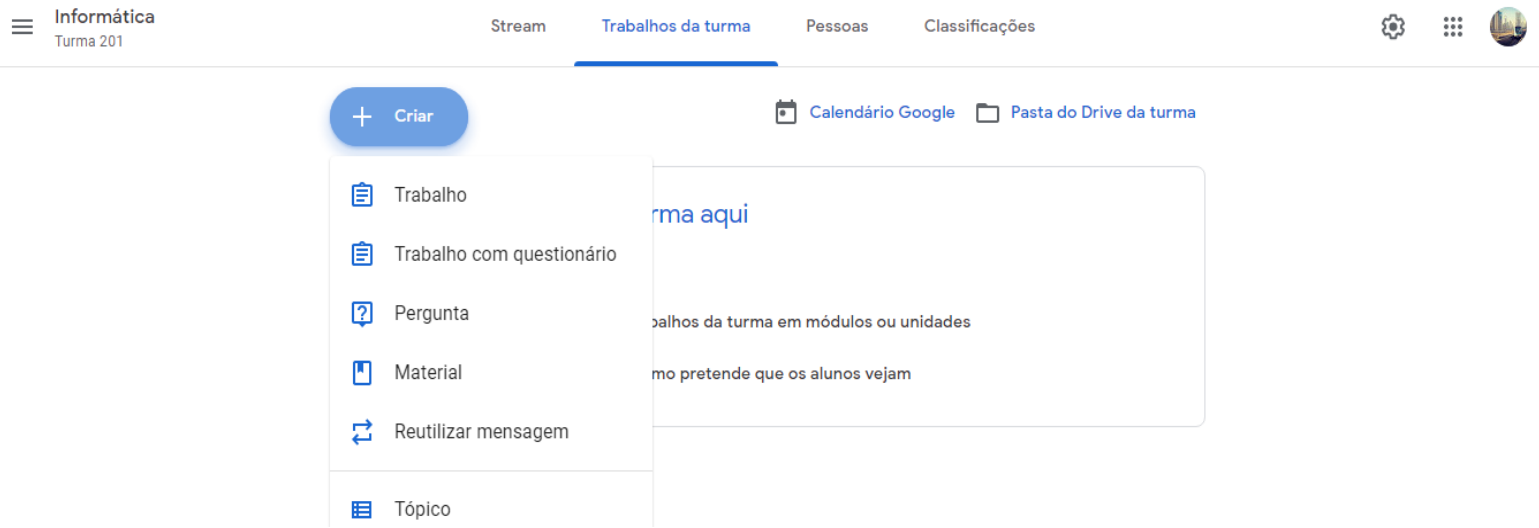

Fonte: Elaborado pelo autor (2020).

Todas as formas de criar atividades, a exemplo das mencionadas na Tabela 1, podem ser postadas, salvas, programadas ou arquivadas. A programação da postagem facilita o planejamento do professor, principalmente quando dispõem de várias turmas (GOOGLE CLASSROOM, 2020).

Tabela 1 - Tipos de atividades realizadas no Google Classroom

\begin{tabular}{|c|l|}
\hline Atividade & $\begin{array}{l}\text { Informação de como a tarefa será avaliada, prazo de conclusão, tarefas com } \\
\text { enunciados curtos e respostas curtas, além da personalização da tarefa. "Nesse } \\
\text { tipo de atividade, a ferramenta sugere que se dê preferência pela realização de } \\
\text { perguntas objetivas". }\end{array}$ \\
\hline Trabalho & $\begin{array}{l}\text { As atividades deste recurso são feitas com o auxílio do Blank Quiz (Google } \\
\text { formulários). Ao escolher essa opção de atividade, a plataforma abre } \\
\text { automaticamente uma criação do forms, assim o professor pode produzir } \\
\text { questionários e, a partir da aplicação deles, identificar os erros, acertos, além do } \\
\text { feedback da pontuação dos alunos na tarefa. } \\
\text { questionário }\end{array}$ \\
\hline Pergunta & $\begin{array}{l}\text { Neste item, o professor pode realizar o fórum. Atividade em que um } \\
\text { questionamento é lançado para os alunos possam discutir e apresentar suas } \\
\text { opiniões sobre uma temática abordada. }\end{array}$ \\
\hline Material & $\begin{array}{l}\text { Permite a postagem de diferentes arquivos multimídia para que sejam } \\
\text { compartilhados na nuvem, via Google Drive, por meio de links, ou até mesmo } \\
\text { em redes e mídias sociais como o YouTube. }\end{array}$ \\
\hline $\begin{array}{c}\text { Reutilizar postagem/ } \\
\text { mensagem }\end{array}$ & $\begin{array}{l}\text { Viabiliza que postagens já usadas em outras turmas possam ser copiadas para } \\
\text { outras. }\end{array}$ \\
\hline
\end{tabular}

Fonte: Elaborado pelo autor (adaptado de Dos Santos Junior e Da Silva Monteiro, 2020). 
Os autores Dos Santos Junior e Da Silva Monteiro (2020) complementam que:

\begin{abstract}
O acesso aos materiais e conteúdos disponibilizados na plataforma são exclusivos dos servidores e estudantes devidamente cadastrados e vinculados ao domínio da instituição. Uma maneira segura contra possíveis invasores de sistemas operacionais como também uma forma de promover a ordenação dos assuntos respectivos à instituição. A plataforma também direciona os materiais a um link com o Google Drive a fim de arquivá-los nas nuvens. Desse modo, a partir do momento em que o professor cria uma nova turma, simultaneamente no Google Drive é formada uma pasta para a sala e possíveis incorporações de exercícios para serem arquivados. Dependendo da necessidade, o professor pode excluir as ações concluídas, mas também adicionar ou reexaminar a qualquer instante no sistema (DOS SANTOS JUNIOR; DA SILVA MONTEIRO, 2020, p. 5).
\end{abstract}

Compreende-se o Google Classroom como proposta de ferramentas assíncronas da educação remota, que são aquelas consideradas desconectadas do momento real e/ou atual: não é necessário que os alunos e professores estejam conectados ao mesmo tempo para que as tarefas sejam concluídas (GOOGLE CLASSROOM, 2020). Dos Santos Junior e Da Silva Monteiro (2020) relatam que essa plataforma online é tão essencial que o professor pode elaborar diversos documentos, inserir vídeos do Youtube, câmera do smartphone ou notebook, apresentações de Powerpoint, $P D F$ e outros. Todos esses registros ficam ao dispor do aluno a fim de ler, estudar e praticar as atividades.

Outras ações pertinentes do Google Classroom são a promoção da autonomia do aluno, permitindo-o a liberdade para acessar o conteúdo a qualquer momento na plataforma, desde que tenha um smartphone, tablet ou computador conectado à internet; otimização da comunicação entre professor e aluno mediado de uma sala de reunião síncrona onde o aluno tira as dúvidas se conectando com o professor de forma interativa.

Portanto, de acordo com o que é citado por Garcia et al. (2015) "que ressaltam a importância e o desenvolvimento dessas tecnologias quanto ao aprendizado por parte dos professores de uma instituição. E isso facilita o relacionamento direto na comunicação entre o professor e o aluno evitando que questionamentos passem despercebidos". Dos Santos Silva, Andrade e Dos Santos (2020, p. 10) relatam que o acesso à internet é "indispensável aos alunos, a participação deles na sala virtual e a frequência em atividades assíncronas como Google Classroom é fundamental para que o professor possa mensurar o nível de aprendizado de todos os alunos".

\title{
3.2 Google Meet e o Aplicativo Zoom
}

Meet e Zoom são uma das maiores plataformas de teleconferência do mundo. Com funcionalidades muito parecidas, essas plataformas são fundamentais para quem necessita efetuar e/ou participar de reuniões em vídeo, de forma online e com segurança, podendo ser executadas em dispositivos móveis (notebooks, smartphones ou tablets). Portanto, a pandemia de COVID-19 influenciou e permitiu que essas plataformas online pudessem proporcionar à comunidade acadêmica as aulas de forma remota. São recursos utilizados por professores para atender as necessidades da instituição de ensino permitindo que os mesmos possam interagir com os alunos de forma síncrona.

As aulas podem ser concebidas no formato de videoconferência: quando proporciona o contato audiovisual entre seus participantes; ou audioconferência: quando possibilita a 
comunicação e a interação seja realizada por meio de áudios. Independente do formato escolhido, também existe a possibilidade de gravar a aula para que ela seja assistida ou ouvida outras vezes - de maneira assíncrona. Assim como acontece na sala de aula presencial, esta modalidade facilita a praticidade para tirar dúvidas (DOS SANTOS JUNIOR; DA SILVA MONTEIRO, 2020, p. 11).

O Meet, exibido na Figura 4, oferecido pelo Google, é uma plataforma gerenciada por dispositivos móveis que permite a conectividade entre o profissional da instituição e alunos no sistema home office. Para Júnior et al. (2017), essa plataforma é gratuita para as escolas que dispõem do sistema e se tornou um dos melhores recursos para o Google desenvolver na área de educação. E, isso, "favorece o professor que pode selecionar o material de estudo ou pesquisa e dentro de sua residência organizar a reunião e enviar um link pelas redes sociais ou e-mail aos convidados" (DOS SANTOS SILVA; ANDRADE, DOS SANTOS, 2020, p. 6).

Figura 4 - Página Inicial do Google Meet

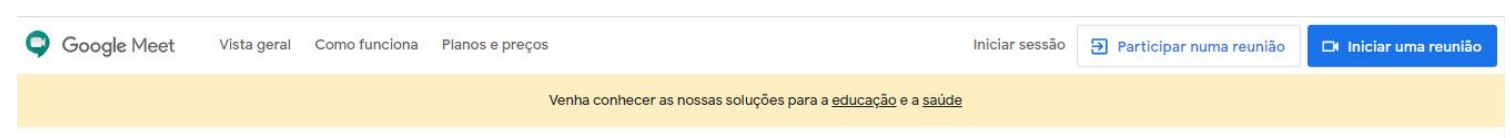

Videoconferências premium. Agora gratuitas para todos.
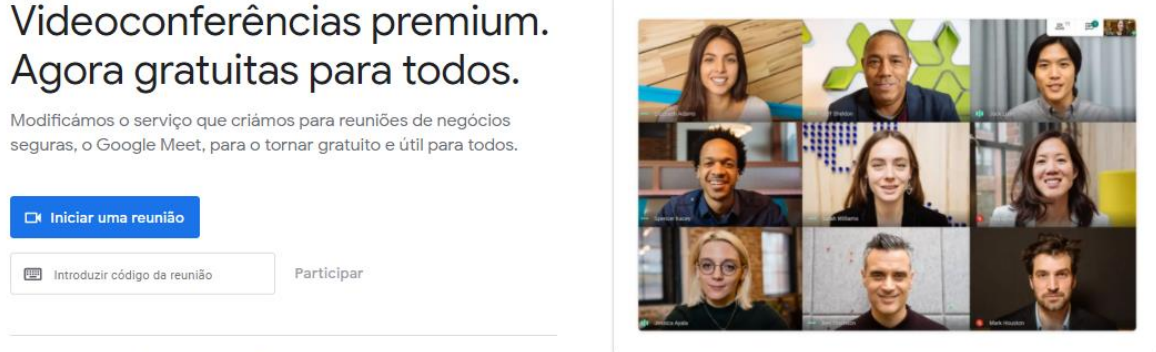

Fonte: Google Meet (2020).

Para Dos Santos Silva, Andrade e Dos Santos (2020),

A vantagem do Meet pelo computador é que não necessita de instalação de aplicativo e o acesso à sala de aula virtual é realizado de modo direto com Google Chrome. O professor ainda pode criar uma reunião e deixar agendada por meio do Google Agenda e adicionar o $e$-mail individual do estudante ou copiar um link para disponibilizar nas redes sociais como WhatsApp ou Instagram facilitando a rápida comunicação entre todos. O sistema, então, prepara a sala para ser acessada pelos integrantes, no entanto, o aluno que não receber o convite, somente participará após a aprovação de outro membro da reunião (DOS SANTOS SILVA, ANDRADE, DOS SANTOS, 2020, p. 7).

Acrescenta-se ainda a realização de reuniões online com duração de até 60 minutos com capacidade até 250 participantes ao mesmo tempo e capacidade que o sistema possui de armazenamento dos dados na nuvem. Os autores Dos Santos Silva, Andrade e Dos Santos (2020, p. 6) citam que o "conteúdo da aula pode ficar disponível aos estudantes que por alguma eventualidade perderam a reunião. Dessa forma, o professor grava o encontro e torna-o acessível a todos para que possam assistir quando desejarem". Para os alunos, "isso facilita o acompanhamento das aulas em tempo real favorecendo o aprendizado remoto, auxiliando o estudante com possíveis dúvidas acerca do assunto e otimizando o trabalho do professor, logo, todos podem interagir pelo chat ou ligando o microfone para falar" (DOS SANTOS SILVA; ANDRADE; DOS SANTOS, 2020, p. 7). 
Nos smartphones Android, é possível também baixar o aplicativo Google Meet pelo Play Store e no iOS fazendo download do mesmo aplicativo para acompanhar as aulas sem a necessidade de um computador ou tablet. E, assim, a conexão vai fluir normalmente e o participante poderá acompanhar a aula por meio do dispositivo sem sair de casa evitando se arriscar ao vírus da COVID-19.

No Zoom é possível convidar os participantes por e-mail, SMS e redes sociais. Sob o lema "Aprendizado moderno para o aluno moderno", (ZOOM, 2020, ONLINE), o aplicativo abriga mais de 17.000 mil instituições educacionais, 96\% delas se tratam das principais universidades dos Estados Unidos da América (EUA), que potencializam o processo de aprendizagem dos alunos usando a ferramenta para aulas virtuais e híbridas, tarefas administrativas e reuniões (DOS SANTOS JUNIOR, DA SILVA MONTEIRO, 2020, p. 10). $\mathrm{Na}$ versão gratuita, a plataforma permite efetuar reuniões virtuais com até 100 participantes, com duração máxima de 40 minutos. Acrescentando, estes autores mencionam que entre os benefícios pedagógicos do aplicativo, compreende-se que ele permite:

a) "O enriquecimento do processo de ensino e o aprendizado para além dos espaços escolares, promovendo competências, estimulando a construção do conhecimento e desenvolvendo um novo paradigma, a aprendizagem ubíqua" (DOS SANTOS JUNIOR; DA SILVA MONTEIRO, 2020).

b) "Potencializa a entrada de tecnologias emergentes no processo formativo do aluno que passam bastante tempo online com seus notebooks, tablets e smartphones, fomentando novos modelos de ensino e diferentes estilos de aprendizagem, transformando o modelo de ensino tradicional que, muitas vezes, não atende mais às demandas da geração de alunos cada vez mais conectada, que quer aprender de forma mais interativa, lúdica e colaborativa" (DOS SANTOS JUNIOR; DA SILVA MONTEIRO, 2020, p. 10).

c) Aumenta os resultados de aprendizagem dos alunos, pois proporciona maior participação nas aulas e retenção do conteúdo transmitido por meio das salas de aula virtuais e híbridas (ZOOM, 2020). Para Dos Santos Junior e Da Silva Monteiro (2020, p. 10) "isso ocorre porque a interatividade entre alunos e professores ocorre de forma síncrona e viabiliza a troca de experiências, bem como, a maturidade do pensamento crítico, relações de flexibilidade na transmissão de opiniões e compreensão mútua, desenvolvendo a inteligência coletiva".

As videoconferências no Zoom são exemplos claros de aulas remotas em ferramentas síncronas, sendo que acontecem com horário marcado via transmissão em tempo real. O aluno é convidado para participar da aula por meio de um link, que o direciona para o encontro virtual no exato momento em que é transmitido (ZOOM, 2020). O professor pode aumentar a participação dos alunos em discussões temáticas, obtendo feedback sobre as principais dúvidas e permitindo que eles façam suas perguntas e sejam valorizados no processo de aprendizagem (DOS SANTOS JUNIOR; DA SILVA MONTEIRO, 2020, p. 11). A Figura 5 mostra a página inicial do Zoom. 
Figura 5 - Página Inicial do Zoom
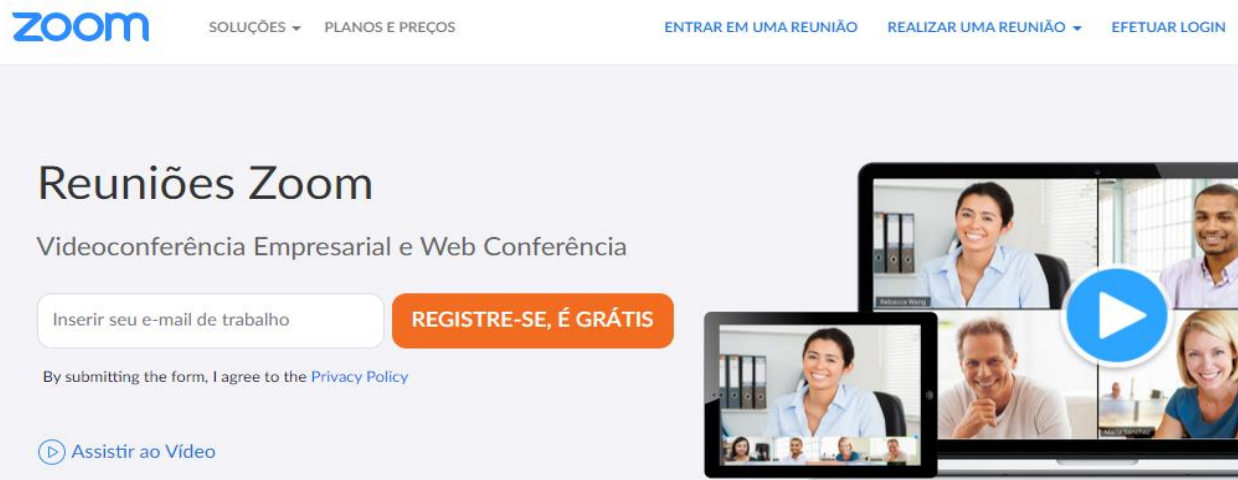

Fonte: Zoom (2020).

Nas aulas remotas síncronas, é imprescindível que o aluno participe ativamente do mesmo jeito que estaria em uma aula presencial. Diante dessa situação, é importante que os professores também devem compreender o papel deles diante do processo educacional, não só usando tecnologias, mas permitindo que o recurso utilizado possa incluir todos os alunos, de forma a atender às necessidades educacionais específicas de cada um (DOS SANTOS JUNIOR, DA SILVA MONTEIRO, 2020, p. 11).

Para Dos Santos Silva, Andrade e Dos Santos (2020) e Dos Santos Junior, Da Silva Monteiro (2020), um ponto positivo de se trabalhar no Google Meet e Zoom é a acessibilidade delas e a demanda de um espaço virtual seguro e eficaz para o rendimento desejado pelas instituições de ensino. São ferramentas simples, de fácil acesso e sem complexidades no seu uso. Um exemplo disso é a possibilidade de compartilhamento de arquivos ou documentos do Powerpoint, Word e PDF, apresentações durante as chamadas (reuniões), compartilhamento de telas ou outras janelas do computador com os participantes da sala para apresentar as atividades, documentos, tarefas, vídeos ou interagir via chat com mensagens para os participantes. O layout oportuniza que todos os participantes apareçam na tela, lado a lado, como se estivessem em sala de aula.

Essas funcionalidades são importantes nesse contexto de isolamento social, visto que as instituições de ensino têm a oportunidade de transmitir as aulas para um grupo de estudantes de forma satisfatória priorizando o ensino-aprendizagem. Os professores não precisam ser Youtuber ou terem qualificação na área de tecnologia para apresentarem as aulas.

Corroborando com este mesmo pensamento, Dos Santos Silva, Andrade e Dos Santos (2020) e Dos Santos Junior, Da Silva Monteiro (2020) afirmam que os recursos disponíveis no Meet e Zoom são fáceis para a utilização e contribuem para uma educação favorável através do espaço virtual reduzindo o distanciamento das aulas presenciais.

Por isso, é importante que o professor busque o aprimoramento das ferramentas do Google Classroom, Google Meet e Zoom para que possa contribuir de forma eficaz na formação dos alunos universitários. Logo, o uso das TDIC vai ser uma modalidade presente na vida de todos, mesmo com as aulas presenciais normalizadas.

\section{Percurso Metodológico}

Das plataformas supracitadas, existem três (3) plataformas que mais se destacam na realização de videoconferências, em Angola: Zoom, Google Meet e Microsoft Teams. Estas ferramentas, atualmente, são das melhores plataformas de videoconferências -e, apresentam 
diversas funcionalidades como gravação de reuniões, partilha de ecrã, facilidade de usar, além de segurança, que é um dos quesitos mais importantes a considerar. Vale destacar que o Zoom tem vantagens sobre o Meet e Microsoft Teams por apresentar recursos avançados de videoconferência e pelo fato de não haver limite para o número de reuniões criadas. $\mathrm{O}$ Meet leva vantagens sobre o Microsoft Teams pela simplicidade no uso e pela solução mais econômica. Entretanto, estes foram os critérios utilizados para selecionar as plataformas online Zoom e Meet. Um dos critérios de seleção do Google Classroom ou Google Sala de Aula foi por ser a plataforma mais escolhida para mediação remota ou na construção de ações pedagógicas para o ensino remoto (a título de exemplo, Brasil), pois não necessita de instalação local e um servidor exclusivo, e que muitos professores desconhecem como ferramenta educacional, como mostram os resultados obtidos nesta pesquisa.

Trata-se de um estudo descritivo e exploratório, que apresenta soluções tecnológicas digitais para o processo de ensino-aprendizagem durante o período de pandemia de COVID19. Quanto ao objetivo deste estudo, define-se como uma pesquisa diagnóstica, que procurou diagnosticar as possíveis percepções dos professores em relação ao uso de TDIC no período de pandemia, sobretudo, das plataformas online Google Sala de Aula, Meet e Zoom. A pesquisa feita foi de natureza qualitativa, fundamentada em Pereira et al.(2018), que a define como "[...] uma metodologia de estudo de fenômenos individuais ou processos sociais".

Dessa forma, esse estudo foi realizado em uma IES pública de Angola, situada na província do Cuanza Sul, município do Sumbe, denominada Instituto Superior Politécnico do Cuanza Sul (ISPCS), a partir de práticas de ensino remoto nos meses de agosto e setembro de 2020, com professor de Informática cujo objetivo era trabalhar as matérias paradas desde o mês de março de 2020 em função da suspensão das atividades presenciais no país inteiro.

Nesse contexto, decidiu-se pesquisar alternativas tecnológicas que pudessem auxiliar ações pedagógicas de ensino-aprendizagem por meio de aulas não presenciais para alunos de graduação do ISPCS, a fim de manter a interação entre professores e alunos em função do reajuste do calendário acadêmico durante o período de pandemia em Angola. Assim sendo, o autor dessa pesquisa encontrou na plataforma do Google os suportes tecnológicos para auxiliar os trabalhos pedagógicos conforme o Decreto Presidencial da República n ${ }^{\circ} 59 / 20$, de 3 de março de 2020, que enfatiza e valoriza a utilização de TDIC para mediação remota do ensino superior nesse período de pandemia. Desse modo, como meio alternativo de interações entre professores e alunos definiu-se o uso das plataformas online Google Classroom, Meet e Zoom, uma vez que são ferramentas adequadas a esse processo de educação remota. Acrescento ainda que as plataformas supracitadas são mais escolhidas para mediação remota em tempos de COVID-19, visto que possibilitam gratuitamente a organização das aulas (turmas e cursos), o cumprimento e a transmissão satisfatória das aulas para os alunos, além de possuírem funcionalidades de fácil utilização.

Para a coleta de dados, foi elaborado um questionário online pela ferramenta Google Forms, cujo link foi enviado aos professores do ISPCS através do grupo do WhatsApp, a fim de explorar suas possíveis percepções em relação ao uso de plataformas como o Google Sala de Aula, Meet e Zoom no período de pandemia da COVID-19. Esse questionário foi estruturado com 18 questões, sendo 16 abertas e 2 fechadas. 25 professores foram convidados a participarem da pesquisa, dos quais 15 responderam ao questionário.

Em relação à técnica de análise de dados, foi usada a análise de conteúdo.

Para o acesso do Google Sala de Aula pelos alunos, é necessário que o professor disponibilize o código da turma criada ou enviar um link aos alunos, e a frequência depende do aluno, ou seja, o aluno pode acessar a plataforma a qualquer momento para visualizar os \# Tear: Revista de Educação Ciência e Tecnologia, v.10, n.1, 2021. 
conteúdos disponibilizados pelo professor, bem como responder as atividades. Para as plataformas Meet e Zoom basta enviar um link pelas redes sociais ou e-mail aos alunos e a frequência é exclusiva ao dia e horário de aula marcado por videoconferência. Ressalvo que para a execução do processo todo é necessário um dispositivo móvel conectado à internet.

\section{Análise dos Resultados}

Participaram da pesquisa 15 professores com o seguinte perfil: 10 do sexo masculino e 05 do sexo feminino, idades que variam de 22 a mais de 49 anos, sendo que 02 possuem idade entre 22 a 30 anos, 07 entre 31 a 39 anos, 02 entre 40 a 49 anos e 04 possuem idade acima de 49 anos, 02 são doutores, 05 são mestres e 08 são licenciados.

Sobre a questão "Você tem conhecimento da existência de plataformas online de apoio ao ensino e aprendizagem?", 12 professores responderam "sim" e apenas 03 responderam "não". Quer dizer que 80\% dos professores afirmaram ter conhecimento da existência de plataformas online de apoio ao ensino e aprendizagem.

Quanto à questão "Você acha fundamental a utilização de plataformas online no processo de ensino-aprendizagem?", todos os 15 professores responderam "sim", totalizando $100 \%$ dos participantes.

Sobre a questão "Você já utilizou alguma plataforma online para auxiliar o processo de ensino-aprendizagem?", 11 professores responderam "sim" e apenas 04 responderam "não".

Quanto à questão "Lhe foi apresentado pela sua instituição alguma solução tecnológica para mediar remotamente suas aulas?", apenas 02 responderam "sim" e 13 responderam "não". Ou seja, 86,7\% dos professores não lhes foi apresentado pela sua IES soluções tecnológicas para mediar remotamente suas aulas nesse período de pandemia da COVID-19, o que indica a necessidade de apresentar plataformas online para que os professores possam mediar remotamente suas aulas.

Sobre a afirmação "Selecione as plataformas abaixo que você conhece", 13 professores selecionaram o aplicativo Zoom, 06 selecionaram o Google Meet, 03 selecionaram o Teams, 07 selecionaram o aplicativo Google Sala de Aula, 04 professores selecionaram a opção "outras" e 01 professor selecionou a opção "nenhuma".

Quanto à questão "Você sabia que os aplicativos Zoom, Meet e Teams são usados para videoconferência de modo gratuito?", 12 professores responderam "sim" e apenas 03 responderam "não".

Sobre a questão "Você sabia que o Google Sala de Aula é uma plataforma gratuita de gerenciamento de conteúdo, em que o professor organiza as turmas, diversifica as formas de avaliações, guarda as atividades e orienta os trabalhos de acordo com a turma escolhida?", apenas 06 participantes responderam "sim" e 09 responderam "não".

Quanto à questão "Você acha necessário receber formação sobre o uso de plataformas como Google Sala de Aula, Zoom e Meet para mediação remota das aulas?", 13 professores responderam "sim", 01 respondeu "talvez" e 01 respondeu "não".

Sobre a questão "Se receber formação sobre o uso de plataformas online (Google Sala de Aula, Zoom e Meet) você usaria no seu trabalho?", 13 docentes responderam "sim" e apenas 02 responderam "talvez". Implica dizer que $86,7 \%$ dos participantes afirmaram utilizar as plataformas online apresentadas neste estudo caso recebam uma oferta de formação. 
Em relação à questão "A pandemia da COVID-19 teve influência na sua atividade pedagógica?", 14 professores responderam "sim" e apenas 01 respondeu "não".

A pesquisa também buscou saber de que forma a pandemia de COVID-19 influenciou nas atividades pedagógicas, na qual os professores comentaram (informação verbal):

Repetição das aulas noutro grupo da turma. Uma vez que as salas de aulas têm uma capacidade de 15 estudantes; Separação dos estudantes;

A transmissão do conhecimento aos estudantes passou a ser de forma intercalada, o que não acontecia antes da pandemia. $O$ estudante frequenta na instituição duas semanas em um mês, outras duas está encontra-se em casa;

$\mathrm{O}$ reajuste do calendário acadêmico diminuiu de certa forma o ritmo das aulas e consequentemente os níveis motivacionais dos alunos. A divisão das turmas em grupo diminuiu para metade a carga horária, o que criou graves transtornos. Se por um lado maior parte das instituições não reúnem condições de internet constante e rápida, por outro o nível econômico dos alunos dificulta a utilização de plataforma digitais, uma larga maioria não possui smartphones e nem tem acesso à internet nas suas comunidades, o que dificulta a utilização de plataformas digitais;

Influenciou negativamente porque tivemos que fazer ajustes nos conteúdos programados;

A demora na transmissão dos conteúdos por causa da divisão da turma em grupos. Por exemplo, por mês apenas duas aulas para os dois grupos;

Na planificação docente, fui forçado a ajustar o programa devido à divisão das turmas; Reduziu o tempo de permanência na sala de aula, por esta razão utilizo as redes sociais para enviar conteúdos das aulas aos estudantes, e para as consultas docentes utilizamos o WhatsApp e o Skype. Por causa da COVID-19 já não é possível reunir todos os estudantes numa sala de aula, tenho que trabalhar com a metade dos alunos, logo não consigo terminar com o programa da disciplina;

Utilizar o WhatsApp e o Facebook para acompanhar os estudantes nos conteúdos programáticos da disciplina em suas casas; inicialmente tive que adicionar a ferramenta Google Classroom como instrumento de ensino mas sem sucesso. Atualmente improvisados as mídias sociais como WhatsApp e Facebook para dar suporte ao ensino;

Influenciou de tal forma que tivemos que dividir as turmas, paralisar os estágios, sendo este uma forma de conciliar a teoria e prática;

Na dinâmica do trabalho em grupo;

Teve influência na paralisação dos estágios dos alunos nos hospitais.

\section{Considerações Finais}

Este artigo preocupou-se em apresentar alternativas de ensino-aprendizagem por meio de plataformas online gratuitas Google Classroom (ferramenta assíncrona), Google Meet e Zoom (ferramentas síncronas) e suas potencialidades pedagógicas para o ensino remoto, sobretudo no ensino superior público angolano, em tempos de COVID-19. Com vistas ao que foi exposto, a mediação das TDIC para o ensino remoto durante o período de isolamento físico e social devido ao COVID-19 e que gerou a suspensão das aulas presenciais nas instituições de ensino angolanas, é possível. Especialmente no que diz respeito às características e funcionalidades do Google Classroom, Google Meet e Zoom.

Não abrange o objetivo deste estudo fazer com que o Google Classroom, Google Meet e Zoom passem a substituir os demais modos de transmitir conhecimento, como o quadro, o giz ou outras tecnologias já existentes. Contudo, elas são apresentadas como recursos educacionais que possibilitam a interação professor/aluno de modo síncrono e/ou assíncrono, sendo capaz de tornar o processo de aprendizagem tão eficaz quanto o ensino presencial, ou seja, tornam a aprendizagem remota mais motivacional, colaborativa, interativa e, sobretudo, significativa. 
O Google Classroom, Google Meet e Zoom foram modificados temporariamente em salas de aulas virtuais, dado que o cenário pandêmico "que se vive não pode interromper o processo formativo de bilhões de pessoas interessadas em colaborar para o avanço de uma sociedade que busca saídas para as diversas crises enfrentados por todos".

Com isso, esse artigo trouxe contribuições para professores, tutores e alunos trabalharem conteúdos didáticos por meio de plataformas online como Google Classroom, Google Meet e Zoom. Disso dependerá o sucesso ou fracasso quando se pretende incentivar os alunos a manterem o interesse pelos estudos neste cenário de suspensão de aulas ou de aulas online, bem como de prosseguirem estudando e frequentarem as aulas presenciais quando o estado de emergência acabar (SAMPAIO, 2020, p. 13).

Todavia, precisa-se refletir sobre a necessidade de adaptação dos alunos e professores angolanos a esse novo momento, bem como aos impactos que tais mudanças podem causar, inclusive, nas condições emocionais de cada sujeito; sobre a inclusão digital e as condições de internet no país.

Espera-se que este estudo, possa auxiliar os professores universitários angolanos que pretendem alternar suas aulas presenciais por meio do ensino remoto e que certos "resultados de aprendizagem podem ser alcançados" com o uso de plataformas online durante e após o período de isolamento físico e social enfrentado desde o ano de 2020.

Deste modo, sugere-se, para a realização de estudos futuros, novas discussões voltadas a alternativas tecnológicas de ensino nesse tempo de pandemia através de pesquisas sobre "estratégias de metodologias ativas como o ensino híbrido, a sala de aula invertida e para atualizar a prática docente" durante o ensino remoto. E, por fim, vale ressaltar que os estudos em Angola continuam, pois, o autor desta pesquisa é angolano, doutorando em uma universidade brasileira e seu projeto de doutorado está vinculado à temática dos laboratórios remotos, que será aplicado em IES do seu país.

\section{Referências}

AGOSTINHO, Fernando Vianeque; SAVETA, Inês Alice. O Uso do Facebook Durante o Estado de Emergência pela COVID-19: experiência com os estudantes de Geografia do Instituto Superior de Ciências da Educação de Benguela. Revista Angolana de Extensão Universitária, v. 2, n. 3, p. 106-130, 2020.

ANGOLA. Decreto Presidencial da República no 59/20, de 3 de março de 2020.

ANGOLA. Decreto Presidencial da República n 81/20, de 25 de março de 2020.

Disponível em: https://www.cisp.gov.ao:10443/wp-content/uploads/2020/04/DP-81-20-

Declara\%C3\%A7\%C3\%A3o-do-estado-de-emerg\%C3\%AAncia_Angola.pdf. Acesso em: 12 maio 2020.

ANGOLA. Decreto Presidencial da República no 97/20, de 9 de abril de 2020.

ANGOLA. Decreto Presidencial da República no 142/20, de 25 de maio de 2020.

Disponível em: https://www.tralac.org/documents/resources/covid-19/countries/3679-angolastatement-on-covid-19-pandemic-25-may-2020/file.html. Acesso em: 29 set. 2020.

ASSOCIAÇÃO DAS UNIVERSIDADES AFRICANAS (AAU). Comunicado de imprensa da AAU sobre a pandemia do Coronavirus (COVID-19): interrupção das actividades 
lectivas e respostas propostas. [30 de mar. 2020]. Disponível em: https://www.aau.org/wpcontent/uploads/sites/9/2020/03/Portuguese-FINAL-THE-AAU-COVID-PRESSRELEASE.pdf. Acesso em: 24 abr. 2020.

BACICH, Lilian; MORAN, José. Metodologias ativas para uma educação inovadora: uma abordagem teórico-prática. Penso Editora, 2018.

ALMEIDA, Maria Elizabeth Bianconcini; VALENTE, José Armando. Integração currículo e tecnologias e a produção de narrativas digitais. Currículo sem fronteiras, v. 12, n. 3, p. 5782, 2012.

CARNEIRO, Leonardo de Andrade; GARCIA, Leandro Guimarães; BARBOSA, Gentil Veloso. Uma Revisão Sobre Aprendizagem Colaborativa Mediada Por Tecnologias. Desafios. Revista Interdisciplinar da Universidade Federal do Tocantins, v. 7, n. 2, p. 52-62, 2020.

CARNEIRO, Leonardo de Andrade; et al. Collaborative Learning in the Military Police of Tocantins: perspective without frontier. International Journal of Advanced Engineering Research and Science, v. 6, n. 7, 2019.

CARNEIRO, Leonardo de Andrade; et al. Uso de tecnologias no ensino superior público brasileiro em tempos de pandemia COVID-19. Research, Society and Development, v. 9, n. 8, p. e267985485-e267985485, 2020.

SANTOS JUNIOR, Verissimo Barros dos; DA SILVA MONTEIRO, Jean Carlos. Educação e COVID-19: As Tecnologias Digitais Mediando a Aprendizagem Em Tempos De

Pandemia. Revista Encantar-Educação, Cultura e Sociedade, v. 2, p. 01-15, 2020.

SILVA, Douglas dos Santos; ANDRADE, Leane Amaral Paz; DOS SANTOS, Silvana Maria Pantoja. Alternativas de ensino em tempo de pandemia. Research, Society and

Development, v. 9, n. 9, p. e424997177-e424997177, 2020.

GARCIA, André de Oliveira; et al. Ferramentas Google: potencialidades de formação continuada para docentes com a formação de competências de domínio tecnológico. Revista Inovaeduc, Campinas, n. 3, 2015.

GOOGLE CLASSROOM. Google for education. [S.1.: s.n.], 2020. Disponível em: classroom.google.com. Acesso em: 25 set. 2020.

IFTAKHAR, Shampa. Google classroom: what works and how. Journal of Education and Social Sciences, v. 3, n. 1, p. 12-18, 2016.

JACINTO, Gercelina Maria Pereira; DE CAMPOS, Paulo Adão; DE CAMPOS, Pascoal Micolo Diogo. Uma Análise SWOT dos Desafios da Educação nos Países da África Subsahariana Ante o COVID-19. Revista Angolana de Extensão Universitária, v. 2, n. 3, p. 11-29, 2020.

JOYE, Cassandra Ribeiro; MOREIRA, Marília Maia; ROCHA, Sinara Socorro Duarte. Distance Education or Emergency Remote Educational Activity: in search of the missing link of school education in times of COVID-19. Research, Society and Development, v. 9, n. 7, 2020.

SOUSA JÚNIOR, Arlindo; et al. Google Suite for education: trazendo o Google Classroom como uma perspectiva para as salas de aula usando os dispositivos móveis. In: CONGRESSO 
SOBRE TECNOLOGIAS NA EDUCAÇÃO, 2., 2017, João Pessoa(PB). [Anais]. João Pessoa (PB) Universidade Federal da Paraíba, 2017.

NEVES JÚNIOR, Idalberto José ; MACHADO, Fabiana de Moura; SILVA, Alexandre dos Santos. Efetividade do uso de ferramentas de ensino à distância como apoio ao ensino presencial, na percepção dos docentes e discentes do curso de ciências contábeis da Universidade Católica de Brasília. In: CONGRESSO USP CONTROLADORIA E CONTABILIDADES, 10., 2010, São Paulo [Anais...] . São Paulo: USP, 2019, p. 1-16.

MARIN, Maria José Sanches et al. Aspectos das fortalezas e fragilidades no uso das metodologias ativas de aprendizagem. Revista brasileira de educação médica, v. 34, n. 1, p. 13-20, 2010.

NOVELLO, Tanise Paula; LAURINO, Debora Pereira. Educação a distáncia: seus cenários e autores. Revista Iberoamericana de Educación, v. 58, n. 4, p. 1-15, 2012.

NOVELLO, Tanise Paula; PEREIRA JUNIOR, Errol Fernando Zepka; RIBEIRO, Nathalia Fehlberg. Ambientes virtuais de aprendizagem: limitações digitais dos professores em época de pandemia do Covid-19. In: SIMPÓSIO NACIONAL DE ESTRATÉGIAS E MULTIDEBATES DA EDUCAÇÃO, SEMEDUC, On-line, 2020. [Anais Eletrônico]. 2020, On-line, p. 1-11.

PEREIRA, A. S., et al. Metodologia da pesquisa científica. Santa Maria. Ed. UAB/NTE/UFSM, 2018. [e-book].

REGUEIRO, Eloisa Maria Gatti ; et al. Ensino mediado por tecnologias no curso de Fisioterapia do Centro Universitário Barão de Mauá durante o período de pandemia da COVID-19. Revista Interdisciplinar de Saúde e Educação, v. 1, n. 1, p. 107-119, 2020.

SAMBO, M. R. B. [Comunicação ]. Mensagem dirigida à Comunidade Académica por ocasião da suspensão das actividades lectivas em todas as Instituições de Ensino Superior. Ministério do Ensino Superior, Ciência, Tecnologia e Inovação. Angola, 20 de março de 2020.

SAMPAIO, Renata Maurício. Teaching and literacy practices in COVID-19 pandemic times. Research, Society and Development, v. 9, n. 7, 2020.

SANZ, Ismael; GONZÁLEZ, Jorge Sáinz ; CAPILLA, Ana. Efeitos da Crise do COVID-19 na Educação. Organización de Estados Iberoamericanos para la Educación, la Ciência y la Cultura (OEI): Área de Educación Superior, Ciencia y ETP, Madrid, 2020. [Relatório].

TELES, Gabriela et al. Docência e Tecnologias Digitais na Formação de Professores: Planejamento e Execução de Aulas por Licenciandos/Teaching and Digital Technologies in Teacher Education: Planning and Execution of Lessons by Graduates. Brazilian Journal of Technology, v. 3, n. 2, p. 73-84, 2020. Disponível em:

http://www.brazilianjournals.com/index.php/BJT/article/view/9459. Acesso em: 4 set. 2020.

UNESCO. Disrupção educacional e resposta COVID-19. 2020. Disponível em: https://en.unesco.org/covid19/educationresponse. Acesso em: 03 de Maio, 2020. 
WILDER-SMITH, Annelies; FREEDMAN, David O. Isolation, quarantine, social distancing and community containment: pivotal role for old-style public health measures in the novel coronavirus (2019-nCoV) outbreak. Journal of travel medicine, v. 27, n. 2, p. 1-4, 2020.

WORLD HEALTH ORGANIZATION (2020). Coronavirus disease 2019 (COVID-19): Situation Report 51. WHO. 2020. Disponível em: https://www.who.int/docs/defaultsource/coronaviruse/situation-reports/20200311-sitrep-51-covid-19.pdf?sfvrsn=1ba62e57_10. Acesso em: 2 out. 2020.

ZOOM. Zoom Cloud Meetings - App. [S.1.: s.n.], 2020. Disponível em: https://zoom.us/ptpt/meetings.html. Acesso em: 03 maio 2020.

Recebido em outubro de 2020.

Aprovado em maio de 2021. 